\title{
Desafios do Sistema Goiano de
}

\section{Inovação}

Este artigo busca apresentar, de forma simplificada e com aplicação específica, os resultados de um trabalho amplo feito pela Secretaria de Ciência de Ciência e Tecnologia de Goiás (Sectec) que procura mapear, identificar por meio de estatísticas e caracterizar estruturalmente toda a produção dos conhecimentos científico, tecnológico e inovador realizados no Estado. Com isso, constitui um verdadeiro sistema de inovação que poderá servir de base para orientar estudos científicos e direcionar investimentos públicos e privados. Todo esforço de mapeamento tem como premissa básica um sistema composto por uma rede de instituições distintas que contribui para o desenvolvimento da capacidade de inovação e aprendizado de uma região. Assim, ele se constitui de elementos que interagem na produção, difusão e uso constante do conhecimento (Cassiolato \& Matos, 2011). Foi com base neste conceito que a Sectec criou o Sistema Goiano de Inovação (Sigo).

O sistema é fruto de estudos técnicos que mostraram a necessidade de reunir em uma plataforma única toda a produção de conhecimento científico, tecnológico e inovador realizado pelas Instituições de Ensino Superior (IES), segmentos empresariais e demais instituições públicas e privadas de pesquisa. Sua implantação representa um salto de qualidade que o estado de Goiás dará rumo a uma economia que agregue cada vez mais valor a seus produtos e serviços através da consolidação de dados e informações e da incorporação do conhecimento.

A justificativa principal do sistema de inovação pode ser dada pela importância que ele vem adquirindo em uma economia globalizada, em que a geração de emprego e renda e a exportação de produtos e serviços passam pela incorporação de tecnologias, operação que, muitas vezes, acarreta dispersão de esforços e desperdício de recursos públicos e privados devido à ausência de um local único que ofereça uma boa base de dados. Neste aspecto, a missão maior do Sigo é monitorar os ambientes de ciência, tecnologia e inovação hospedados em Goiás, criando e promovendo uma sinergia entre oferta e demanda por conhecimento tecnológico.

Vale ressaltar que no mundo moderno, a agilidade de informações tornou-se questão de sobrevivência para governos, empresas e instituições de pesquisa. Neste sentido, ações públicas e privadas bem articuladas estimulam a criação de projetos inovadores que podem promover o desenvolvimento socioeconômico de um estado. Pensando de forma sistêmica, o Sigo está fundamentado numa plataforma operacional composta pelas redes de ciência, tecnologia e inovação; de formação profissional; de meteorologia; e de difusão e reaplicação de tecnologias sociais. Desta forma, envolve a interação, cooperação e aprendizagem dos participantes da rede com o potencial de gerar incremento da capacidade inovadora de Goiás (Vieira \& Costa, 2011).

As empresas têm buscado cada vez mais internacionalizar suas atividades intensivas em conhecimento e, ao mesmo tempo, abrirem seus processos de inovação para colaboração de parceiros externos (fornecedores, clientes, universidades, dentre outros). Nesse cenário desafiador, para superar novas barreiras mercadológicas, se faz importante a disponibilização de dados e informações para a prospecção de bons negócios, do acirramento da competitividade com produtos e serviços com médios e altos conteúdos tecnológicos, e a inovação.

Os desafios desta nova era provocam soluções criativas e inovadoras que são mensuradas pela sociedade constantemente por uma relação de custo e benefício. $\mathrm{O}$ processo é sistêmico e só adquire significância econômica através de exercícios extensos de redesenho, modificação e de milhares de pequenos e grandes aperfeiçoamentos (Rosenberg, 1976). Os desafios por inovação são compreendidos e enfrentados a partir do método de tentativa e erro, com adição cumulativa de pequenas e 
grandes modificações dos processos produtivos e desenho de produtos, envolvendo firmas com fortes ligações, em vez de unidades isoladas e completamente independentes (Imai \& Baba, 1989).

A inovação é um processo interativo, entre suas diversas fases, desde a pesquisa básica até a comercialização e difusão do conhecimento. Um sistema, que não é bem um ato simples e bem definido, mas uma série de atos proximamente ligados ao processo inventivo e aos sujeitos envolvidos. Assim, o Sigo é mais uma janela de oportunidades que se abre diante de vários desafios que são postos por políticas que precisam do envolvimento de toda sociedade do conhecimento e da produção. Para isso, Cassiolato \& Matos (2011) destacam algumas políticas necessárias:

1) C,T\&I - para assegurar a geração e difusão de conhecimento no curto e longo prazo;

2) Concorrência - para aumentar o efeito motor da competição sobre a Inovação, mas também para facilitar a $\mathrm{P} \& \mathrm{D}$ cooperativa;

3) Educação e formação - para desenvolver o capital humano necessário;

4) Reforma administrativa - para reduzir as sobrecargas administrativas e a rigidez institucional;

5) Financeiras e fiscais - para facilitar a migração de capital para as PMES de base tecnológica;

6) Emprego - para aumentar a mobilidade de pessoal e aumentar os fluxos de conhecimento tácito;

7) Comunicações - para maximizar a disseminação de informação;

8) Comerciais e de investimento estrangeiro - para fortalecer a difusão de tecnologia em nível global;

9) Regionais - para melhorar a complementaridade entre iniciativas governamentais de níveis diferentes.
Enfim, políticas de fomento e sistematização de dados e informações são cruciais para o desenvolvimento de uma região. As possibilidades de multiplicação do conhecimento passam por sua utilização de forma cada vez mais intensa. Neste sentido, o maior desafio para o sistema goiano de inovação é mapear toda a produção de ciência, tecnologia e inovação goiana e disponibilizála em tempo real para os segmentos que querem agregar valor aos seus produtos e serviços.

\section{Referências}

1. Cassiolato, J. E. \& Matos, M.P. Inovação e Sistemas de Inovação. Painel no Curso de Sistemas de Inovação e Políticas Públicas, Goiânia: MCTI/CEPAL, julho/2011.

2. Imai, K-I \& Baba, Y. Systemic innovation and cross-border networks. Paper apresentado no International Seminar on Science, Technology and Economic Growth. Paris: OECD. 1989.

3. Rosenberg N. Perspectives on Technology. Cambridge: Cambridge University Press, 1976.

4. Vieira, J. C \& Costa, P.C. Inovação: o porvir de Goiás. IN Conjuntura Econômica Goiana, Vol. 18. Goiânia: Segplan/SEPIN. Outubro/2011.

\section{Jeferson C. Vieira ${ }^{\text {* }}$ \& Wagno P. Costa $^{2}$}

${ }^{1}$ Superintendente de Desenvolvimento Tecnológico, Inovação e Fomento à Tecnologia da Informação da Secretaria de Estado de Ciência e Tecnologia de Goiás.

${ }^{2}$ Assessor Especial da Secretaria de Estado de Ciência e Tecnologia de Goiás.

*e-mail: jefersoncvieira@uol.com.br 